\title{
Biochemical Characterization of Bovine Brain Myristoyl-CoA:Protein N-Myristoyltransferase Type 2
}

\author{
Ponniah Selvakumar, Ashakumary Lakshmikuttyamma, and Rajendra K. Sharma \\ Department of Pathology and Laboratory Medicine, College of Medicine and Health Research Division, Saskatchewan Cancer Agency, \\ University of Saskatchewan, 20 Campus Drive, Saskatoon, SK, Canada S7N 4H4
}

Correspondence should be addressed to Rajendra K. Sharma, rajendra.sharma@saskcancer.ca

Received 6 February 2009; Revised 9 June 2009; Accepted 15 June 2009

Recommended by Matthew B. Wheeler

Protein N-myristoylation is a lipidic modification which refers to the covalent attachment of myristate, a 14-carbon saturated fatty acid, to the N-terminal glycine residue of a number of mammalian, viral, and fungal proteins. In this paper, we have cloned the gene coding for myristoyl-CoA:protein N-myristoyltransferase (NMT) from Bos tarus brain. The open reading frame codes for a 410-amino-acid protein and overexpressed in Escherichia coli. Kinetic studies suggested that bovine brain NMT2 and human NMT1 show significant differences in their peptide substrate specificities. The metal ion $\mathrm{Ca}^{2+}$ had stimulatory effects on NMT2 activity while $\mathrm{Mn}^{2+}$ and $\mathrm{Zn}^{2+}$ inhibited the enzyme activity. In addition, NMT2 activity was inhibited by various organic solvents and other detergents while NMT1 had a stimulatory effect. Biochemical characterization suggested that both forms of NMT have unique characteristics. Further analysis towards functional role NMT2 will lead the development of therapeutic target for the progression of various diseases such as cancer, cardiovascular diseases, and neurodegenerative diseases.

Copyright () 2009 Ponniah Selvakumar et al. This is an open access article distributed under the Creative Commons Attribution License, which permits unrestricted use, distribution, and reproduction in any medium, provided the original work is properly cited.

\section{Introduction}

Protein N-myristoylation is a lipidic modification which refers to the covalent attachment of myristate, a 14-carbon saturated fatty acid, to the $\mathrm{N}$-terminal glycine residue of a number of mammalian, viral, and fungal proteins [1-8]. In general, $\mathrm{N}$-myristoylation is an irreversible cotranslational protein modification which occurs after removal of the initiator methionine residue by methionine aminopeptidases $[7,8]$. However, there is an instance where $\mathrm{N}$-myristoylation occurs posttranslationally as is the case of proapoptotic protein BID where it is cleaved by caspase 8 , to reveal a myristoylation motif [9], at aspartate 60 and aspartate 75 to generate truncated BID forms that facilitate release of mitochondrial cyctochrome c [10]. N-myristoylation ensures the proper functioning and intracellular trafficking of proteins. Many proteins involved in a wide variety of signal cascades; cellular transformations and oncogenesis are myristoylated [1-8].

Myristoylation of proteins is catalyzed by the ubiquitously distributed eukaryotic enzymes $\mathrm{N}$-myristoyltrans- ferase (NMT) which is a member of the GNAT superfamily of proteins [1-8]. Despite recent advances in the protein myristoylation field, the specificities of the various NMTs and the differences in species specificity among various putative isoenzymes are yet to be undertaken. Biochemical evidence has indicated the presence of several distinct NMTs in vivo, often varying in either apparent molecular weight and/or subcellular distribution. We provided the first evidence for the existence of multiple forms of bovine brain NMT [11]. In addition, Mcllhinney et al. [12] identified two forms of NMT in bovine brain cortex. Subsequently, Glover and Felsted [13] showed that bovine brain exists as a heterogeneous mixture of NMT subunits. Two types of NMT, NMT1, and NMT2, were identified. NMT1 was extensively studied from various sources $[14,15]$. The biochemical characterization of NMT2 is yet to be explored. Comparisons between the NMT1 and NMT2 proteins revealed reduced levels of sequence identity (76-77\%), indicating that NMT1 and NMT2 comprise two distinct families of NMTs [14]. The specific inhibition or regulation of either NMT in vivo may in turn allow for the selective control of particular myristoylation-dependent cellular functions. 
We have reported that NMT activity and expression were elevated in rat [16] and human colon carcinomas [17]. In addition, we reported high expressions of both NMT1 and NMT2 in human brain tumors [18] and human colorectal cancer [18]. Also we have also demonstrated the interaction of various signaling molecules such as $\mathrm{m}$-calpain, caspase-3, p53, and Bcl2 with NMT1 and NMT2 in human colorectal cancer [19]. It is clearly established that both forms of NMT have a unique functional role in the progression of various diseases such as cancer, cardiovascular diseases, and neurodegenerative diseases $[20,21]$. The present study was undertaken to examine the biochemical characterization of bovine brain NMT2 to distinguish from NMT1.

In this paper, we report the molecular cloning, expression, and biochemical characterizations of NMT2 from $B$. tarus brain. Kinetic studies suggested that bovine brain NMT2 and human NMT1 show significant differences in their peptide substrate specificities. The metal ions $\mathrm{Ca}^{2+}$, $\mathrm{Mn}^{2+}$, and $\mathrm{Zn}^{2+}$ inhibited the enzyme activity. In addition, NMT2 activity was inhibited by various organic solvents and other detergents while NMT1 had a stimulatory effect.

\section{Materials and Methods}

2.1. Materials. $\left[9,10-{ }^{3} \mathrm{H}\right]$ myristic acid was purchased from Perkin-Elmer, Canada. Pseudomonas acyl-CoA synthetase, and coenzyme A were obtained from Sigma. pQE-9 was purchased from Qiagen, Canada. Restriction endonucleases and DNA modifying enzymes were purchased from Amersham Pharmacia Biotech. Ligation Pack was purchased from New England Biolabs, USA. Anti-NMT2 was obtained from BD biosciences, Canada. General laboratory chemicals were of analytical grade. The following peptides were synthesized by the Alberta Peptide Synthesis, Alberta, Canada. Gly-Asn-AlaAla-Ala-Ala-Lys-Lys-Arg-Arg (based on the $\mathrm{NH}_{2}$-terminal sequence of the type I1 catalytic subunit of cAMP-dependent protein kinase), Gly-Ser-Ser-Lys-Ser-Lys-Pro-Lys-Arg (the $\mathrm{NH}_{2}$-terminal sequence of pp60 $0^{\mathrm{Src}}$ ), Gly-Asn-Ala-Ser-SerIle-Lys-Lys-Lys (the $\mathrm{NH}_{2}$-terminal sequence of the $\mathrm{M} 2$ gene segment of reovirus type 3, and Gly-Ala-Gln-Phe-Ser-LysThr-Ala-Arg-Arg (the $\mathrm{NH}_{2}$-terminal sequence of myristoylated alanine-rich $\mathrm{C}$ kinase substrate (MARCKS)).

2.2. Molecular Cloning, Expression, and Purification of Recombinant NMT2. General cloning techniques were carried out essentially as described by Sambrook et al. [22]. Total RNA was prepared using the RNeasy Mini Kit (Qiagen, Hilden, Germany). PCR with degenerate oligonucleotides was used to amplify a DNA fragment encoding the NMT2. Sense and antisense oligonucleotide primers were designed based on retina NMT2 (AF222687). The sense oligonucleotide ( $5^{\prime}$ GGA TCC ATG GCG GAG GAC AGC GAG TC-3', BamHI restriction site) and antisense oligonucleotide ( $5^{\prime}$-AAG CTT CTA CTG TAA TAC GAG TCC AAC CTT TTC AGA C-3', HindIII restriction site). PCR was performed with the total RNA as a template in a GeneAmp PCR System 2400 (Applied Biosystems) for 35 cycles (each consisting of denaturation at $94^{\circ} \mathrm{C}$ for 30 seconds, annealing at $51^{\circ} \mathrm{C}$ for 30 seconds, and extension at $72^{\circ} \mathrm{C}$ for 1 minute) using One Step RT-PCR kit (Qiagen). Amplified PCR products were cloned into the Zero Blunt Topo vector (Invitrogen), and their DNA sequences were determined and designated as pZeroBlunt NMT2. The vector PQE9 was treated with BamHI and HindIII. An insert NMT2 gene was prepared by digestion of clone pZeroBlunt NMT2 and purified by agarose gel electrophoresis. The insert was ligated with vector and used to transform $E$. coli M13. The recombinant plasmid was purified and designated pQE9-NMT2.

E. coli M13 cells transformed with pQE-9 were grown at $37^{\circ} \mathrm{C}$ in Luria-Bertani medium containing $100 \mu \mathrm{g} / \mathrm{mL}$ ampicillin until the optical density at $600 \mathrm{~nm}$ reached about 0.5 . Then isopropylthio- $\beta$-galactopyranoside (IPTG) was added to the culture at the final concentration of $1 \mathrm{mM}$, and cultivation was continued for an additional 5 hours at $37^{\circ} \mathrm{C}$. Bacterial cells were harvested by centrifugation and resuspended in $1 \mathrm{~mL}$ of lysis buffer $(50 \mathrm{mM}$ Tris- $\mathrm{HCl}, \mathrm{pH}$ 8.0, $300 \mathrm{mM} \mathrm{NaCl}, 10 \mathrm{mM}$ imidozol). They were then lysed by addition of lysozyme to a final concentration of $1 \mathrm{mg} / \mathrm{mL}$ on ice for 30 minutes followed by sonication in a Sonics and Materials VibraCell Sonicator, for $6 \times 10 \mathrm{~s}$ bursts. The lysate was cleared by centrifugation $\left(10000 \mathrm{~g}, 30\right.$ minutes at $4^{\circ} \mathrm{C}$ ) and loaded on to an Ni-NTA affinity column, equilibrated with lysis buffer. The column was washed extensively with wash buffer ( $50 \mathrm{mM}$ Tris- $\mathrm{HCl}, \mathrm{pH} 8.0,300 \mathrm{mM} \mathrm{NaCl}$ and $20 \mathrm{mM}$ imidozol), and then the bound protein was eluted from the column using elution buffer $(50 \mathrm{mM}$ Tris- $\mathrm{HCl}$, $\mathrm{pH}$ 8.0, $300 \mathrm{mM} \mathrm{NaCl}$, and $250 \mathrm{mM}$ imidozol). The purity of brain NMT2 was analyzed by sodium dodecyl sulfatepolyacrylamide gel electrophoresis (SDS-PAGE) and the purified fractions were pooled and stored at $-80^{\circ} \mathrm{C}$ for further analysis.

2.3. NMT Assay and Kinetics. NMT activity was measured as previously described [23]. For the standard enzyme assays, the reaction mixture contained $0.4 \mu \mathrm{M}\left[{ }^{3} \mathrm{H}\right]$ myristoyl-CoA, $50 \mathrm{mM}$ Tris- $\mathrm{HCl}, \mathrm{pH}$ 7.8, $0.5 \mathrm{mM}$ EGTA, $0.1 \%$ Triton X$100,500 \mu \mathrm{M}$ synthetic peptide, and purified NMT2 in a total volume of $25 \mu \mathrm{L}$. The reaction was initiated by the addition of radiolabeled $\left[{ }^{3} \mathrm{H}\right]$ myristoyl-CoA and incubated at $30^{\circ} \mathrm{C}$ for 10-30 minutes. The reaction was terminated by spotting aliquots of incubation mixture onto P81 phosphocellulose paper discs and drying them under a stream of warm air. The P81 phosphocellulose paper discs were washed in three changes of $40 \mathrm{mM}$ Tris- $\mathrm{HCl}, \mathrm{pH} 8.0$, for 90 minutes. The radioactivity was quantified in $7.5 \mathrm{~mL}$ of Beckman Ready Safe Liquid Scintillation mixture using a Beckman Liquid Scintillation Counter. One unit of NMT activity was expressed as $1 \mathrm{pmol}$ of myristoyl-peptide formed per minute per mg protein. Kinetics studies were carried out by varying the enzyme and peptide concentrations.

2.4. Effect of Metal Ions, Organic Solvents, Detergents on NMT2. To determine the effect of metal ions on NMT2 activity, we incubated the purified NMT2 with various concentrations (0-5 mM) of $\mathrm{Ca}^{2+}, \mathrm{Mn}^{2+}, \mathrm{Mg}^{2+}, \mathrm{Fe}^{2+}$, or $\mathrm{Zn}^{2+}$ in the reaction mixture and the effect of NMT2 activity was 


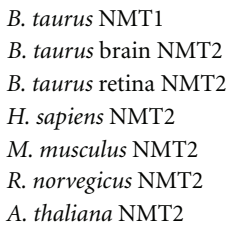

B. taurus NMT1

B. taurus brain NMT2

B. taurus retina NMT2

H. sapiens NMT2

M. musculus NMT2

R. norvegicus NMT2

A. thaliana NMT2

B. taurus NMT1

B. taurus brain NMT2

B. taurus retina NMT2

H. sapiens NMT2

M. musculus NMT2

R. norvegicus NMT2

A. thaliana NMT2

B. taurus NMT1

B. taurus brain NMT2

B. taurus retina NMT2

H. sapiens NMT2

M. musculus NMT2

R. norvegicus NMT2

A. thaliana NMT2

B. taurus NMT1

B. taurus brain NMT2

B. taurus retina NMT2

H. sapiens NMT2

M. musculus NMT2

R. norvegicus NMT2

A. thaliana NMT2

\section{B. taurus NMT1 \\ B. taurus brain NMT2 \\ B. taurus retina NMT2 \\ H. sapiens NMT2 \\ M. musculus NMT2 \\ R. norvegicus NMT2 \\ A. thaliana NMT2}

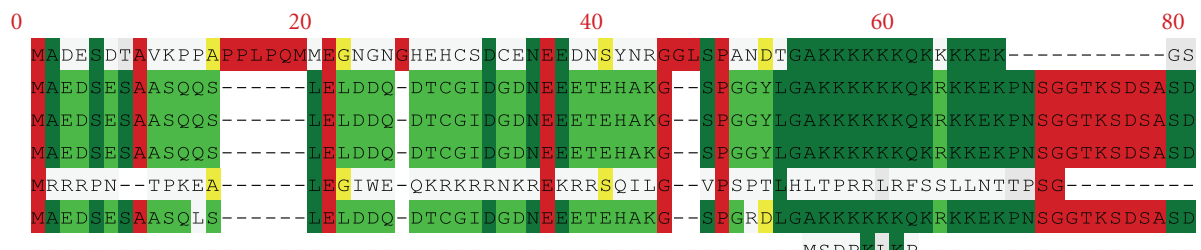

80
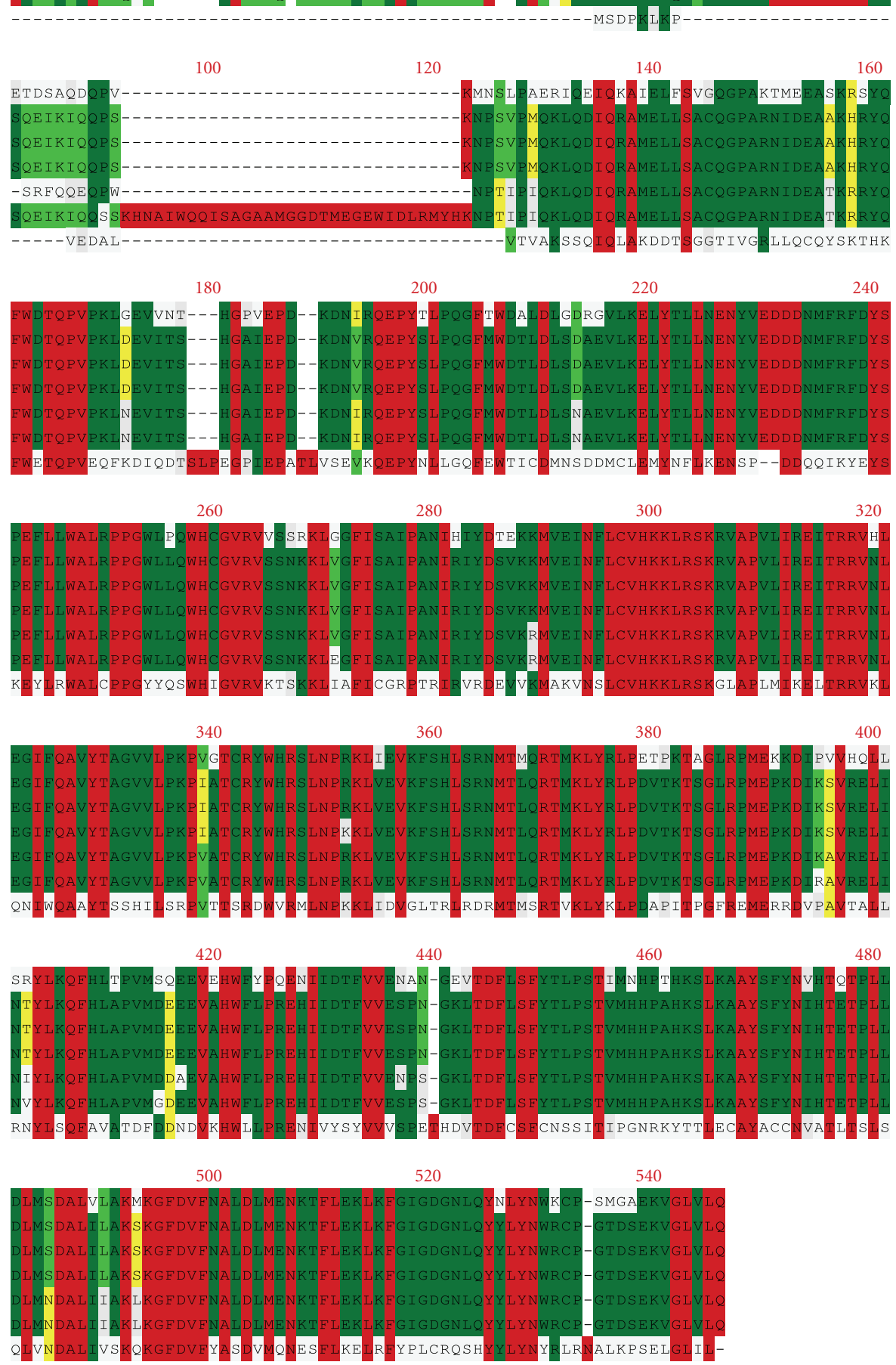

FIGURE 1: Comparison of the amino acid sequences of different species of NMT2. The multiple sequence alignment was generated using the ClustralW program. The conservation is represented by the following colors: primary (red, 90-100\%), secondary (green, 70-89\%), tertiary (light green, 50-69\%), and quaternary (yellow, 30-49\%). The deduced amino acid sequence of bovine brain NMT2 was aligned with B. taurus retina, AAA73914; H. sapiens, NP005337; M. musculus, AAC84169; R. norvegicus, CAA52328; A. thaliana; AAC23421; NMT1 B. taurus, BC109533. 
assayed as described above. The NMT2 activity was carried out in the presence of SDS (0-10 mM), ethanol (0-25\%), and acetonitrile (0-25\%) using cAMP-dependent protein kinase as peptide substrate.

2.5. SDS-Polyacrylamide Gel Electrophoresis and Western Blot Analysis. Thirty micrograms of total cellular protein were resolved on a $10 \%$ SDS-PAGE according to the procedure described by Laemmli [24]. Gel transfer to nitrocellulose membrane and blocking were performed using standard procedures [25]. The blot was incubated with the NMT2 antibodies at $1: 1000$, washed and probed with an antimouse IgG horseradish peroxidase conjugate diluted 1 : 2000. Membranes were then incubated in chemiluminescence reagents and exposed to Kodak X-OMAT Blue XB-1 film for detection. The blot was reprobed with $\beta$-actin after stripping for 30 minutes in $62.4 \mathrm{mM}$ Tris- $\mathrm{HCl}, \mathrm{pH} 6.8$, and $2 \%$ SDS containing $10 \mathrm{mM} \beta$-mercaptoethanol at $60^{\circ} \mathrm{C}$.

2.6. Other Methods. Protein concentration was measured by the method of Bradford [26] using bovine serum albumin as the standard. The nucleotide and amino acid sequences were evaluated using the MacVector computer program.

\section{Results and Discussion}

N-Myristoylation of proteins is a cotranslational event [1-8], and it appears to play an important role in mediating specific protein-protein or protein-lipid interactions, ligand-induced protein conformational changes, and subcellular targeting [1-8]. The enzyme responsible for this modification, NMT, has been extensively studied in yeast and mammalian cells because NMT is a potential target for anticancer, antiviral, antifungal, and antineoplastic therapy [1-3]. Various reports including our laboratory demonstrated that both forms of NMT have a unique functional role in the progression of various diseases such as cancer, cardiovascular diseases, neurodegenerative diseases. The present study was undertaken to examine the biochemical characterization of bovine brain NMT2 to distinguish from NMT1. In addition, very little information is available about NMT2 in myristoylation.

3.1. Cloning of Bovine Brain NMT2. In order to clone NMT2 from bovine brain, total RNA from bovine brain was reverse transcribed to cDNA using One-Step RT-PCR Kit. The degenerate primers for NMT2 were designed based on the DNA sequences of bovine retina NMT2 [27]. These primers amplified an expected PCR product of $\sim 1.5 \mathrm{~kb}$. The amplified cDNA was cloned into pZeroBlunt vector and the complete nucleotide sequence was determined. The single long open reading frame (1494bp) of bovine brain tissue NMT2 specifies a protein of 498 amino acids. Sequence analysis revealed that bovine brain NMT2 has 99\% homology to retina NMT2 at amino acid level. To analyze the similarity of bovine brain NMT2 with other NMT2 family proteins, we compared the amino acid sequence of various species of NMT2 using ClustralW program. The bovine brain NMT2 exhibited 100\% similarity with Homo sapiens,

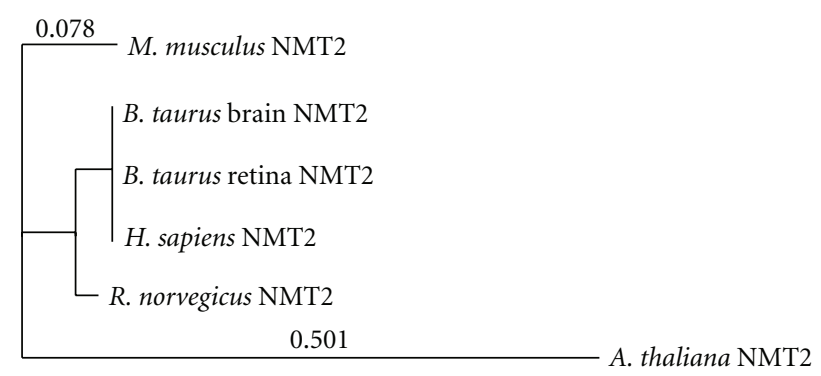

\section{1}

FIGURE 2: Molecular phylogenetic tree of the amino acid sequences of NMT2s from various species. The tree was constructed by the neighbor joining method, based on sequence information.

91.9\% with Rattus norvegicus, $86.4 \%$ with Mus musculus, and 51.6\% with Arabidopsis thaliana (Figure 1). A high degree of sequence conservation was observed in $\mathrm{NH}_{2}$-terminal sequence of different species. Within the coding region there is $92.4 \%$ identity with the human NMT1 at the nucleotide level [2]. The bovine NMT1 exhibited $83.2 \%$ similarity with bovine brain, retina and $H$. sapiens NMT2, 79.4\% with M. musculus NMT2, 77.9\% with $R$. norvegicus NMT2, and $52.5 \%$ with $A$. thaliana NMT2.

3.2. Phylogenetic Analysis of NMT2. Phylogenetic analysis of NMT2 family reveals that it can be grouped into three major families (Figure 2). Group one family is composed of proteins from $A$. thaliana, the second family consists of $R$. norvegicus, $H$. sapiens, and B. Taurus, and the third family consists of M. musculus. The second family further subgrouped into $R$. norvegicus, $H$. sapiens, and $B$. taurus. The phylogenetic tree suggested that $B$. taurus belongs to the second group.

3.3. Expression and Purification of Bovine Brain NMT2. Subsequently, the cDNA of NMT2 was subcloned in to the expression vector pQE9 and transformed in to E. coli M13 (pREP4). For the purification of recombinant brain NMT2, the crude cell lysate was applied to Ni-NTA Agarose column and the bound His ${ }_{6}$-NMT2 was eluted as described in the experimental procedures. This single step purification was sufficient to produce highly purified recombinant brain NMT2 as judged by coomassie staining of samples resolved by SDS-PAGE (Figure 3(a)). The molecular mass of purified brain NMT2 was $50 \mathrm{kDa}$. Furthermore, a monoclonal antibody raised against brain NMT2 was immunoreactive towards the recombinant brain NMT2 protein (Figure 3(b)). This is in general agreement with previous studies of other NMTs that gave molecular mass of $50-60 \mathrm{kDa}$ for monomeric human [29,30], $50 \mathrm{kDa}$ for bovine spleen [31] and cardiac muscle [20], $55 \mathrm{kDa}$ for yeast [32], $53 \mathrm{kDa}$ for Candida albicans [33], and $46 \mathrm{kDa}$ for Drosophila [34]. However, NMTs from murine leukemia cell line L1210 [35] and bovine brain [13] have been demonstrated to exist in multiple isoforms. 
TABLE 1: Peptide substrate specificity of the recombinant bovine brain NMT2. The recombinant bovine brain NMT2 assay was measured in the presence of varying concentrations of various peptide substrates $(0-1000 \mu \mathrm{M})$. The reaction was carried out as described in Section 2 . The data shown represent the mean of three replicates. The human NMT1 values were adopted from [28]. Peptides derived from known mammalian $N$-Myristoyl proteins.

\begin{tabular}{lcccc}
\hline Peptide sequence & Km & & Vmax & \\
& Bovine NMT2 & Human NMT1 & Bovine NMT2 & Human NMT1 \\
\hline GSSKSKPKR $^{\mathrm{a}}$ & 5.3 & 44 & 88 & 120 \\
GNAAAAKKRR $^{\mathrm{b}}$ & 44 & 115 & 48 & 95 \\
GNASSIKKK $^{\mathrm{b}}$ & 8.5 & 136 & 72 & 66.8 \\
\hline
\end{tabular}

a Peptide derived from NH2-terminal sequence of $p p 600^{\text {src }}$.

${ }^{b}$ Peptide derived from NH2-terminal sequence of cAMP-dependent protein kinase.

'Peptide derived from NH2-terminal sequence of M2 gene segment of reovirus type 3.

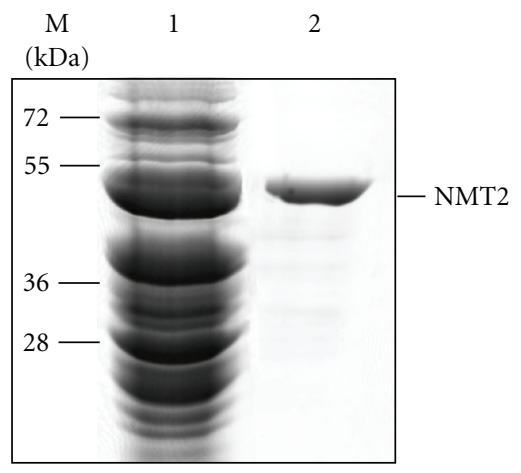

(a)

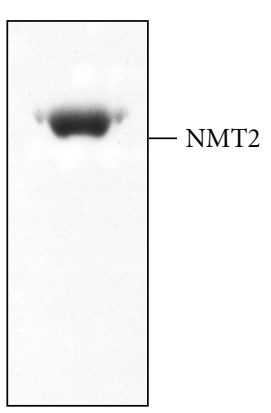

(b)

FIGURE 3: SDS-PAGE and Western blot analysis of bovine brain NMT2. Thirty microgram of proteins was loaded onto (a) SDSPAGE; lane 1, crude cell lysate; lane 2, purified E. coli expressed bovine brain NMT2. (b) Purified E. coli expressed bovine brain NMT2 (thirty microgram) immunoblotted with monoclonal antiNMT2 (1:1000 dilution) as described in Section 2.

3.4. Kinetic Studies of NMT2. Comparative studies of peptide substrate specificities between bovine brain NMT2 and human NMT1 enzymes revealed significant differences in their respective catalytic efficiencies (the details are summarized in Table 1). The results suggested that bovine brain NMT2 had lower Km values towards pp60 $6{ }^{\text {src }}$ peptide sequence than other peptide sequence. The peptide derived from cAMP-dependent protein kinase exhibited a 2.6-fold lower $\mathrm{Km}$ value than human NMT1. Interestingly, bovine brain NMT2 showed a 16-fold lower Km toward peptide derived from M2 gene while 8.3 folds lower toward peptide derived from $\mathrm{pp} 60^{\mathrm{src}}$. Taken together, the results clearly suggest that bovine brain NMT2 and human NMT1 show significant differences in their peptide substrate specificities.

3.5. Effect of Metal Ions. We examined the effect of various divalent cations on NMT2. The metal ion $\mathrm{Ca}^{2+}$ had stimulatory effects on NMT2 activity at lower concentration $(0.25 \mathrm{mM})$ while higher concentration showed inhibition of enzyme activity and $40 \%$ of the NMT2 enzyme activity inhibited at $5 \mathrm{mM}$ concentration (Figure 4(a)).
The myristoylated MARCKS, a major in vivo substrate of protein kinase $\mathrm{C}$, interacts with plasma membranes in a phosphorylation-, myristoylation-, and calmodulindependent manner [28]. Therefore, we interested to examine the effect of calmodulin (CaM) on NMT2 activity and observed that there was no significant effect of CaM on NMT2 activity (Figure 4(b)). We observed a 50\% loss of enzyme activity by $\mathrm{Mn}^{2+}$ at $5 \mathrm{mM}$ concentration. Interestingly, $\mathrm{Zn}^{2+}$ showed maximum inhibition compared to other divalent cations tested and $80 \%$ of the enzyme activity was abolished at $5 \mathrm{mM}$ concentration (Figures $4(\mathrm{c})$ and 4(e)). The metal ions $\mathrm{Mg}^{2+}$ had negligible effects on NMT2 activity, indicating that the enzyme does not require these divalent cations for its activity (Figure 4(d)). The metal ions $\mathrm{Mg}^{2+}$, $\mathrm{Ca}^{2+}$, and $\mathrm{Mn}^{2+}$ had negligible effects on Arabidopsis NMT1 activity, indicating that the enzyme does not require these divalent cations for its activity [36].

3.6. Effect of SDS on NMT2. Another interesting finding observed in this study was that NMT2 was found to be activated 2.5 folds with SDS. The optimum concentration was found to be $3.0 \mathrm{mM}$ (Figure 5). These results suggest that a mild concentration of detergent could open the structure of NMT2, thereby allowing NMT2 to become highly active. However at higher concentrations of SDS, NMT2 activity was totally inactivated, suggesting that there is an optimum level of structural changes in NMT2. Results also suggest that some thiol group(s) in NMT2 could be masked inside the protein. In the presence of SDS, these thiol group(s) could be unmasked and thereby reactive. Human NMT1 was found to be activated several folds with SDS and optimum concentration was found to be $1.73 \mathrm{mM}$ [37]. It has been reported that in aldolase, one thiol per subunit reacts readily, but an additional three groups react if a small amount of detergent is added [38]. Human NMT has been shown to be susceptible towards N-5,5' dithiobis (2-nitrobenzoic acid) (DTNB) and iodoacetamide, suggesting the implication of cysteine requirement for the enzyme catalysis [39]. Comparison of four yeasts and one human NMT protein sequences revealed that 2 cysteine residues at amino acids 169 and 214 in human NMT and 172 and 217 in yeast NMT were highly conserved [40,41]. Bovine spleen NMT has been shown to be activated several folds with SDS [42]. 


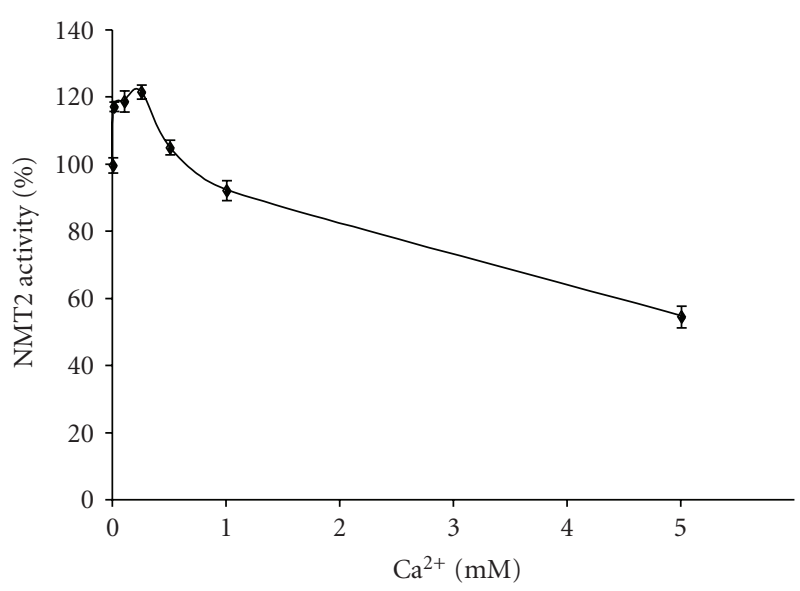

(a)

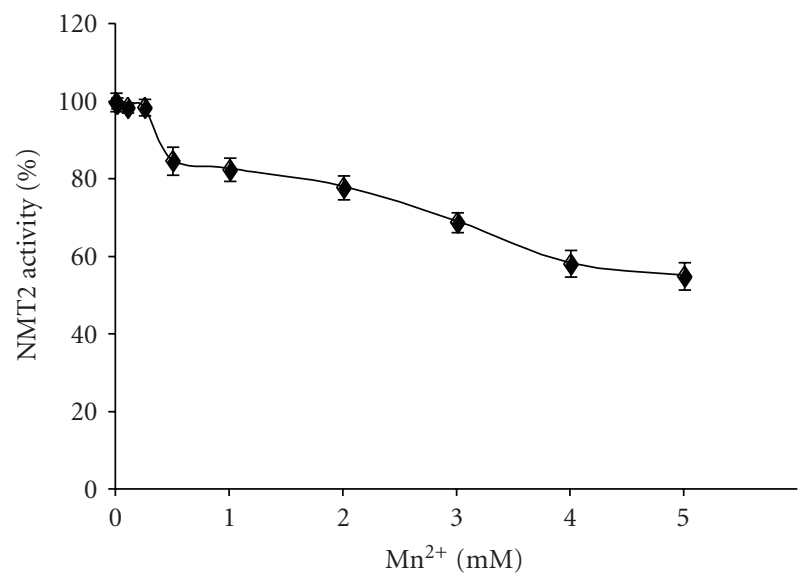

(c)

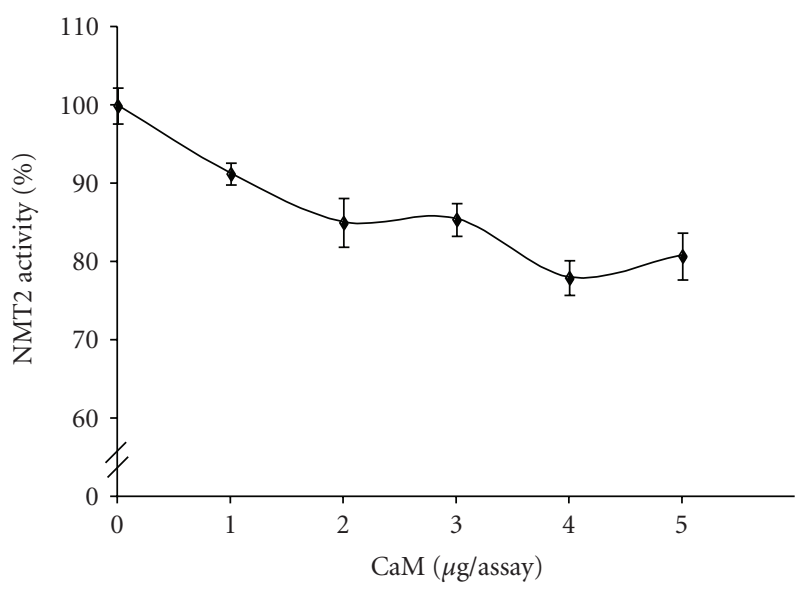

(b)

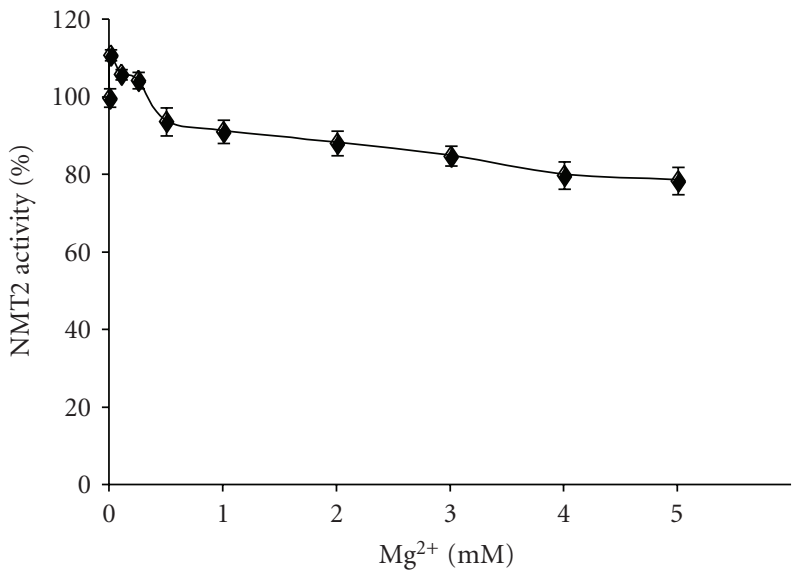

(d)

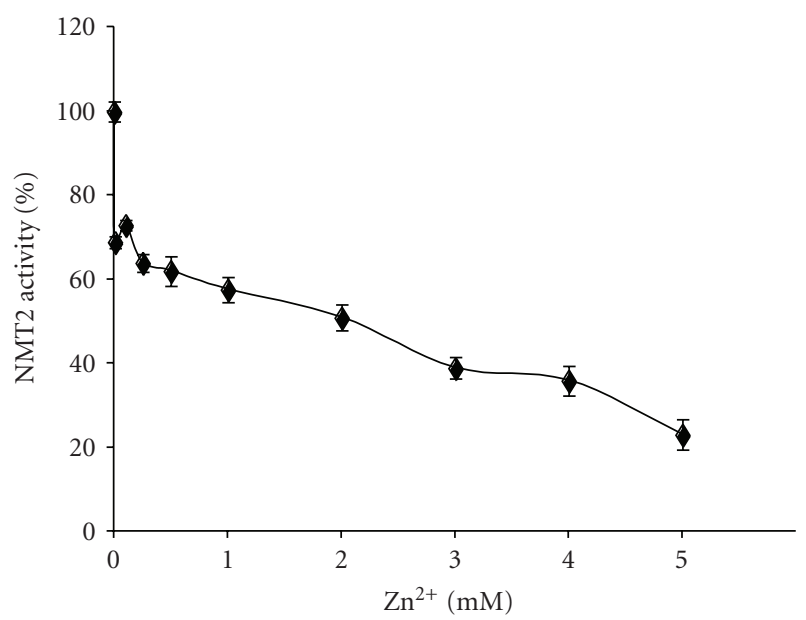

(e)

FIGURE 4: Effect of metal ions on bovine brain NMT2 activity. Bovine brain NMT2 (1.0 $\mu \mathrm{g} /$ assay) activity was determined in the presence of carrying concentrations of (a) $\mathrm{Ca}^{2+}$, (b) $\mathrm{CaM}$, (c) $\mathrm{Mn}^{2+}$, (d) $\mathrm{Mg}^{2+}$, and (e) $\mathrm{Zn}^{2+}$ using cAMP-dependent protein kinase derived peptide substrate $(1.0 \mathrm{mM})$. The reactions were initiated by the addition of $0.27 \mu \mathrm{M}\left[{ }^{3} \mathrm{H}\right]$ myristoyl CoA and incubated at $30^{\circ} \mathrm{C}$ for 30 minutes. The data presented are representative of at least three separate experiments. 


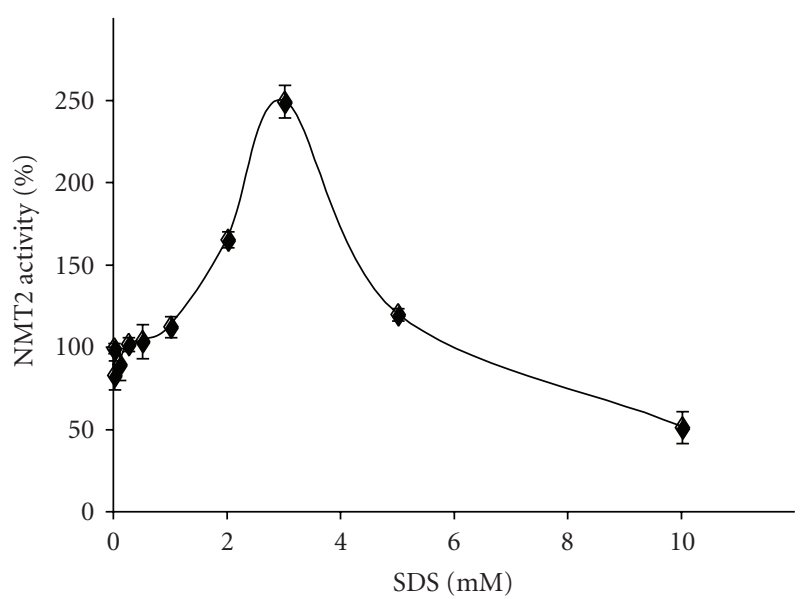

FIGURE 5: Effect of SDS on bovine brain NMT2 activity. Bovine brain NMT2 $(1.0 \mu \mathrm{g} /$ assay) activity was determined in the presence of carrying concentrations of SDS (0-10 mM) using cAMPdependent protein kinase derived peptide substrate $(1.0 \mathrm{mM})$. The reactions were initiated by the addition of $0.27 \mu \mathrm{M}\left[{ }^{3} \mathrm{H}\right]$ myristoyl $\mathrm{CoA}$ and incubated at $30^{\circ} \mathrm{C}$ for 30 minutes. The data presented are representative of at least three separate experiments.

3.7. Effect of Organic Solvents on NMT2. We investigated the effect of ethanol and acetonitrile on NMT2 and we observed that the NMT2 activity was inhibited by ethanol and acetonitrileat the concentration of 15 and $10 \%$, respectively, (Figure 6). Like bovine spleen NMT [43], human NMT was also found to be activated several folds with organic solvents such as ethanol and acetonitrile [43]. It has been reported that ethanol enhances the stimulatory effect of insulin and insulin-like growth factor-1 on DNA synthesis in NIH 3T3 fibroblasts [44]. It has also demonstrated that ethanol enhances the expression of cell surface class I major histocompatibility complex antigens in a variety of cell lines [45]. Also reported is that ethanol activates nonactivated phosphorylase kinase at $\mathrm{pH} 6.8$, similar to the activation achieved by phosphorylation at two specific sites on phosphorylase kinase by cAMP dependent protein kinase [46]. It appears from these studies that ethanol could act as a second messenger in the signal transduction pathway to further propagates the signals such as substrate expression, substrate accessibility, or regulation of NMT activity.

In conclusion, we have provided a biochemical characterization of bovine brain NMT2. Bovine brain NMT2 differs from human NMT1 with respect to its peptide substrate preference. The metal ion $\mathrm{Ca}^{2+}, \mathrm{Mn}^{2+}$, and $\mathrm{Zn}^{2+}$ inhibited the NMT2 enzyme activity. In addition, NMT2 activity was inhibited by various organic solvents and other detergents while NMT1 had a stimulatory effect. The availability of NMT2 gene, recombinant NMT2 protein, antibody, and information regarding NMT2 protein properties will facilitate further investigations to determine the role(s) of protein $\mathrm{N}$-myristoylation as well as to define NMT protein targets in various chronic diseases such as cancer, cardiovascular diseases, and neurological diseases.

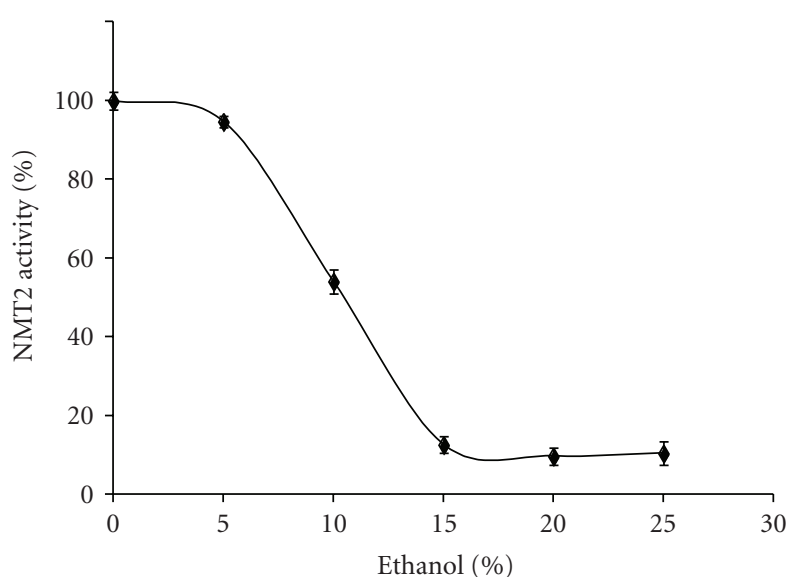

(a)

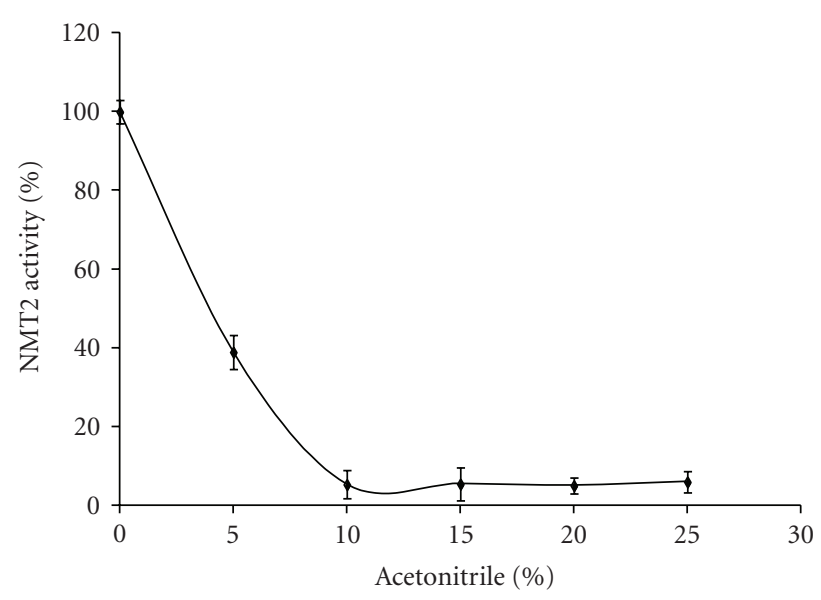

(b)

FIGURE 6: Effect of ethanol (a) and acetonitrile (b) on bovine brain NMT2. Bovine brain NMT2 (1.0 $\mu \mathrm{g}$ /assay) activity was determined in the presence of carrying concentrations (0-25\%) of ethanol and acetonitril using cAMP-dependent protein kinase derived peptide substrate $(1.0 \mathrm{mM})$. The reactions were initiated by the addition of $0.27 \mu \mathrm{M}\left[{ }^{3} \mathrm{H}\right]$ myristoyl CoA and incubated at $30^{\circ} \mathrm{C}$ for 30 minutes. The data presented are representative of at least three separate experiments.

\section{Acknowledgments}

This work is supported by the Canadian Institutes for Health Research, Canada. The authors are thankful to Mr. F. Mark Boyd for the technical work.

\section{References}

[1] A. Lakshmikuttyamma, P. Selvakumar, J. Tuchek, and R. K. Sharma, "Myristoyltransferase and calcineurin: novel molecular therapeutic target for epilepsy," Progress in Neurobiology, vol. 84, no. 1, pp. 77-84, 2008.

[2] P. Selvakumar, A. Lakshmikuttyamma, A. Shrivastav, S. B. Das, J. R. Dimmock, and R. K. Sharma, "Potential role of Nmyristoyltransferase in cancer," Progress in Lipid Research, vol. 46, no. 1, pp. 1-36, 2007. 
[3] P. Selvakumar and R. K. Sharma, "Role of calpain and caspase system in the regulation of $\mathrm{N}$-myristoyltransferase in human colon cancer," International Journal of Molecular Medicine, vol. 19, no. 5, pp. 823-827, 2007.

[4] P. Selvakumar and R. K. Sharma, "Phosphorylation and dephosphorylation of human myristoyltransferase type 1," Canadian Journal of Physiology and Pharmacology, vol. 84, no. 7, pp. 707-712, 2006.

[5] P. Selvakumar, M. K. Pasha, L. Ashakumary, J. R. Dimmock, and R. K. Sharma, "Myristoyl-CoA:protein Nmyristoyltransferase: a novel molecular approach for cancer therapy," International Journal of Molecular Medicine, vol. 10, no. 4, pp. 493-500, 2002.

[6] J. A. Boutin, "Myristoylation," Cellular Signalling, vol. 9, no. 1, pp. 15-35, 1997.

[7] M. D. Resh, "Fatty acylation of proteins: new insights into membrane targeting of myristoylated and palmitoylated proteins," Biochimica et Biophysica Acta, vol. 1451, no. 1, pp. 1-16, 1999.

[8] P. Selvakumar, A. Lakshmikuttyamma, J. R. Dimmock, and R. K. Sharma, "Methionine aminopeptidase 2 and cancer," Biochimica et Biophysica Acta, vol. 1765, no. 2, pp. 148-154, 2006.

[9] J. Zha, S. Weiler, K. J. Oh, M. C. Wei, and S. J. Korsmeyer, "Posttranslational N-myristoylation of BID as a molecular switch for targeting mitochondria and apoptosis," Science, vol. 290, no. 5497, pp. 1761-1765, 2000.

[10] M. Degli Esposti, G. Ferry, P. Masdehors, J. A. Boutin, J. A. Hickman, and C. Dive, "Post-translational modification of Bid has differential effects on its susceptibility to cleavage by caspase 8 or caspase 3," The Journal of Biological Chemistry, vol. 278, no. 18, pp. 15749-15757, 2003.

[11] M. J. King and R. K. Sharma, "Demonstration of multiple forms of bovine brain myristoyl CoA:protein N-myristoyl transferase," Molecular and Cellular Biochemistry, vol. 113, no. 1, pp. 77-81, 1992.

[12] R. A. J. McIlhinney, K. McGlone, and A. C. Willis, "Purification and partial sequencing of myristoyl-CoA:protein $\mathrm{N}$ myristoyltransferase from bovine brain," Biochemical Journal, vol. 290, no. 2, pp. 405-410, 1993.

[13] C. J. Glover and R. L. Felsted, "Identification and characterization of multiple forms of bovine brain $\mathrm{N}$ myristoyltransferase," The Journal of Biological Chemistry, vol. 270, no. 39, pp. 23226-23233, 1995.

[14] D. K. Giang and B. F. Cravatt, "A second mammalian Nmyristoyltransferase," The Journal of Biological Chemistry, vol. 273, no. 12, pp. 6595-6598, 1998.

[15] D. R. Rundle, R. V. S. Rajala, and R. E. Anderson, "Characterization of type I and type II myristoyl-CoA:protein Nmyristoyltransferases with the Acyl-CoAs found on heterogeneously acylated retinal proteins," Experimental Eye Research, vol. 75, no. 1, pp. 87-97, 2002.

[16] B. A. Magnuson, R. V. S. Raju, T. N. Moyana, and R. K. Sharma, "Increased N-myristoyl-transferase activity observed in rat and human colonic tumors," Journal of the National Cancer Institute, vol. 87, no. 21, pp. 1630-1635, 1995.

[17] R. V. S. Raju, T. N. Moyana, and R. K. Sharma, "Nmyristoyltransferase overexpression in human colorectal adenocarcinomas," Experimental Cell Research, vol. 235, no. 1, pp. 145-154, 1997.

[18] Y. Lu, P. Selvakumar, K. Ali, et al., "Expression of Nmyristoyltransferase in human brain tumors," Neurochemical Research, vol. 30, no. 1, pp. 9-13, 2005.
[19] P. Selvakumar, E. Smith-Windsor, K. Bonham, and R. K. Sharma, "N-myristoyltransferase 2 expression in human colon cancer: cross-talk between the calpain and caspase system," FEBS Letters, vol. 580, no. 8, pp. 2021-2026, 2006.

[20] R. V. S. Raju, R. Kakkar, R. S. S. Datla, J. Radhi, and R. K. Sharma, "Myristoyl-CoA:protein N-myristoyltransferase from bovine cardiac muscle: molecular cloning, kinetic analysis, and in vitro proteolytic cleavage by $m$-calpain," Experimental Cell Research, vol. 241, no. 1, pp. 23-35, 1998.

[21] M. K. Pasha, R. K. Sharma, and A. H. Rajput, "Increased myocardial N-myristoyltransferase activity in rotenone model of Parkinsonism," International Journal of Molecular Medicine, vol. 15, no. 6, pp. 987-991, 2005.

[22] J. Sambrook, E. F. Fritsch, and T. Maniatis, Molecular Cloning: A Laboratory Manual, Cold Spring Harbor Laboratory, Cold Spring Harbor, NY, USA, 2nd edition, 1989.

[23] M. J. King and R. K. Sharma, "N-myristoyl transferase assay using phosphocellulose paper binding," Analytical Biochemistry, vol. 199, no. 2, pp. 149-153, 1991.

[24] U. K. Laemmli, "Cleavage of structural proteins during the assembly of the head of bacteriophage T4," Nature, vol. 227, no. 5259, pp. 680-685, 1970.

[25] H. Towbin, T. Staehelin, and J. Gordon, "Electrophoretic transfer of proteins from polyacrylamide gels to nitrocellulose sheets: procedure and some applications," Proceedings of the National Academy of Sciences of the United States of America, vol. 76, no. 9, pp. 4350-4354, 1979.

[26] M. M. Bradford, "A rapid and sensitive method for the quantitation of microgram quantities of protein utilizing the principle of protein dye binding," Analytical Biochemistry, vol. 72, no. 1-2, pp. 248-254, 1976.

[27] D. R. Rundle, R. V. S. Rajala, R. A. Alvarez, and R. E. Anderson, "Myristoyl-CoA:protein N-myristoyltransferases: isoform identification and gene expression in retina," Molecular Vision, vol. 10, pp. 177-185, 2004.

[28] Q. Qi, R. V. S. Rajala, W. Anderson, et al., "Molecular cloning, genomic organization, and biochemical characterization of myristoyl-CoA:protein N-myristoyltransferase from Arabidopsis thaliana," The Journal of Biological Chemistry, vol. 275, no. 13, pp. 9673-9683, 2000.

[29] R. J. Duronio, S. I. Reed, and J. I. Gordon, "Mutations of human myristoyl-CoA:protein N-myristoyltransferase cause temperature-sensitive myristic acid auxotrophy in Saccharomyces cerevisiae," Proceedings of the National Academy of Sciences of the United States of America, vol. 89, no. 9, pp. 41294133, 1992.

[30] C. J. Glover, K. D. Hartman, and R. L. Felsted, "Human $\mathrm{N}$-myristoyltransferase amino-terminal domain involved in targeting the enzyme to the ribosomal subcellular fraction," The Journal of Biological Chemistry, vol. 272, no. 45, pp. 28680-28689, 1997.

[31] R. V. S. Raju, J. Kalra, and R. K. Sharma, "Purification and properties of bovine spleen N-myristoyl-CoA protein:Nmyristoyltransferase," The Journal of Biological Chemistry, vol. 269, no. 16, pp. 12080-12083, 1994.

[32] D. A. Towler, S. P. Adams, and S. R. Eubanks, "Purification and characterization of yeast myristoyl CoA:protein Nmyristoyltransferase," Proceedings of the National Academy of Sciences of the United States of America, vol. 84, no. 9, pp. 27082712, 1987.

[33] R. C. Wiegand, C. Carr, J. C. Minnerly, et al., "The Candida albicans myristoyl-CoA:protein N-myristoyltransferase gene. Isolation and expression in Saccharomyces cerevisiae and 
Escherichia coli," The Journal of Biological Chemistry, vol. 267, no. 12, pp. 8591-8598, 1992.

[34] M. Ntwasa, M. Egerton, and N. J. Gay, "Sequence and expression of Drosophila myristoyl-CoA:protein N-myristoyl transferase: evidence for proteolytic processing and membrane localisation," Journal of Cell Science, vol. 110, no. 2, pp. 149-156, 1997.

[35] J. A. Boutin, G. Ferry, A.-P. Ernould, P. Maes, G. Remond, and M. Vincent, "Myristoyl-CoA:protein N-myristoyltransferase activity in cancer cells. Purification and characterization of a cytosolic isoform from the murine leukemia cell line L1210," European Journal of Biochemistry, vol. 214, no. 3, pp. 853-867, 1993.

[36] M. Matsubara, K. Titani, H. Taniguchi, and N. Hayashi, "Direct involvement of protein myristoylation in myristoylated alanine-rich C kinase substrate (MARCKS)-calmodulin interaction," The Journal of Biological Chemistry, vol. 278, no. 49, pp. 48898-48902, 2003.

[37] R. V. S. Raju, R. S. S. Datla, and R. K. Sharma, "Expression of human N-myristoyltransferase in Escherichia coli. Comparison with $\mathrm{N}$-myristoyltransferases expressed in different tissues," Molecular and Cellular Biochemistry, vol. 155, no. 1, pp. 69-76, 1996.

[38] J. Nicolau and M. Bacila, "N-acylsarcosines as inhibitors of respiration and glycolysis and glycolytic enzymes," Archives of Biochemistry and Biophysics, vol. 129, no. 1, pp. 357-361, 1969.

[39] R. A. J. McIlhinney, P. B. Patel, and K. McGlone, "Characterization of a polyhistidine-tagged form of human myristoylCoA:protein N-myristoyltransferase produced in Escherichia coli," European Journal of Biochemistry, vol. 222, no. 1, pp. 137146, 1994.

[40] R. J. Duronio, D. A. Towler, R. O. Heuckeroth, and J. I. Gordon, "Disruption of the yeast N-myristoyl transferase gene causes recessive lethality," Science, vol. 243, no. 4892, pp. 796$800,1989$.

[41] S. M. Peseckis and M. D. Resh, "Fatty acyl transfer by human $\mathrm{N}$-myristyl transferase is dependent upon conserved cysteine and histidine residues," The Journal of Biological Chemistry, vol. 269, no. 49, pp. 30888-30892, 1994.

[42] R. V. S. Raju, B. A. Magnuson, and R. K. Sharma, "Mammalian myristoyl CoA:protein N-myristoyltransferase," Molecular and Cellular Biochemistry, vol. 149-150, pp. 191-202, 1995.

[43] R. V. S. Rajala and R. K. Sharma, "Myristoyl, CoA:protein Nmyristoyltransferase: subcellular localization, activation and kinetic behavior in the presence of organic solvents," Biochemical and Biophysical Research Communications, vol. 208, no. 2, pp. 617-623, 1995.

[44] M. Tomono and Z. Kiss, "Ethanol enhances the stimulatory effects of insulin and insuin-like growth factor-1 on DNA synthesis in NIH 3 T3 fibroblasts," Biochemical and Biophysical Research Communications, vol. 208, no. 1, pp. 63-67, 1995.

[45] L. J. Parent, R. Ehrlich, L. Matis, and D. S. Singer, "Ethanol: an enhancer of major histocompatibility complex antigen expression," The FASEB Journal, vol. 1, no. 6, pp. 469-473, 1987.

[46] T. J. Singh and J. H. Wang, "Stimulation of glycogen phosphorylase kinase from rabbit skeletal muscle by organic solvents," The Journal of Biological Chemistry, vol. 254, no. 17, pp. 84668472, 1979. 

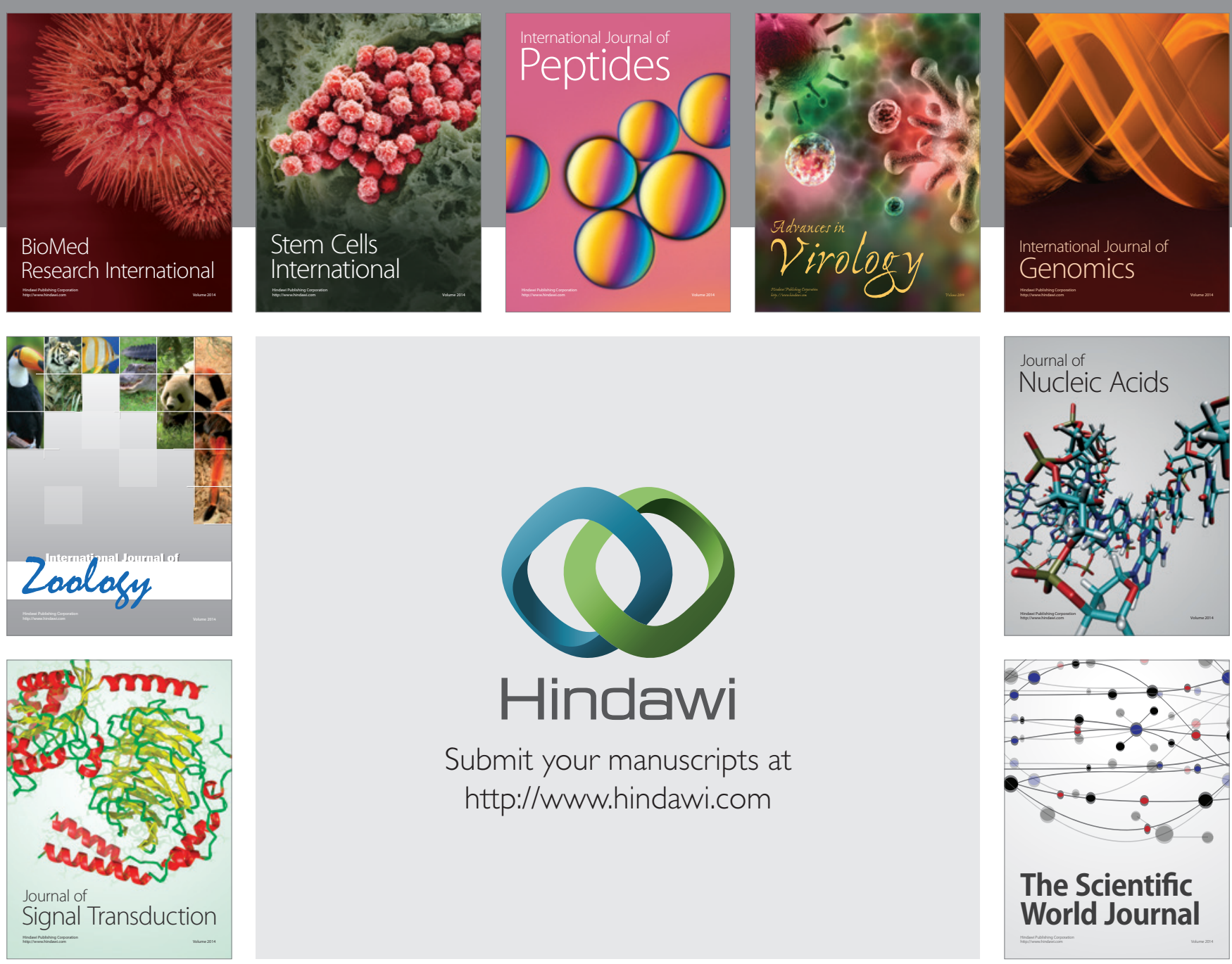

Submit your manuscripts at

http://www.hindawi.com
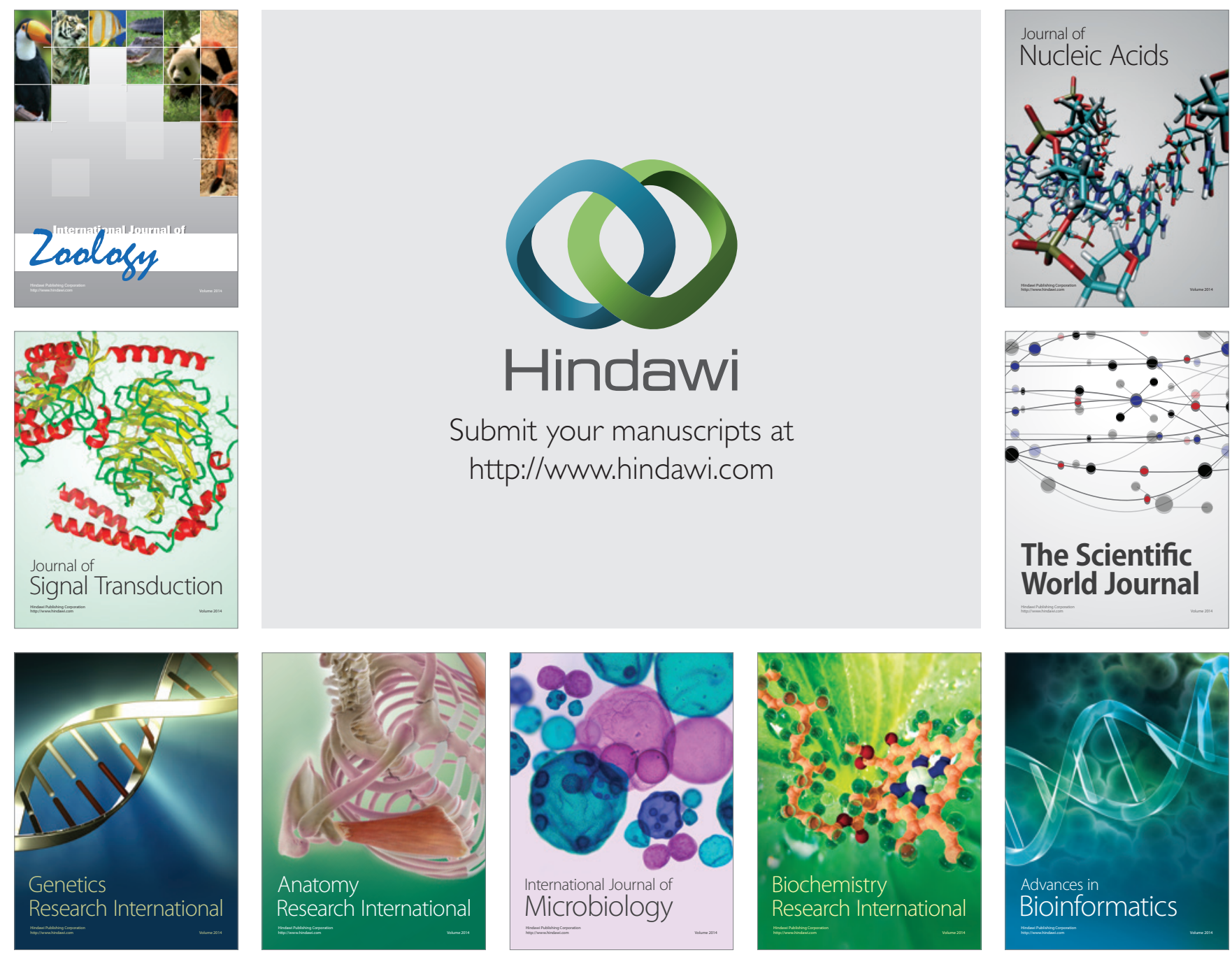

The Scientific World Journal
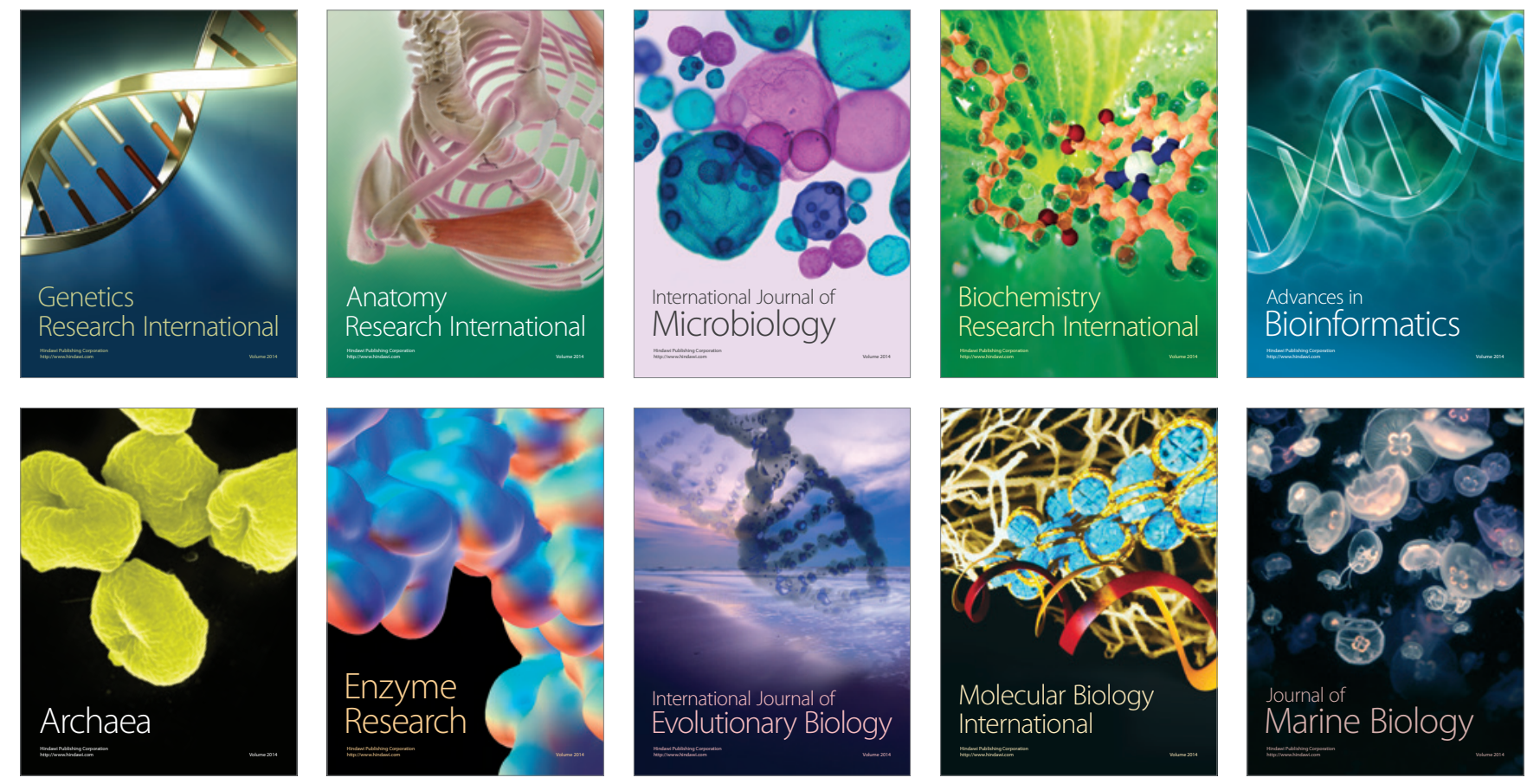